\title{
IN VITRO METABOLISM OF COPALIC AND KAURENOIC ACIDS IN RAT AND HUMAN LIVER MICROSOMES
}

\author{
Mariana Mauro ${ }^{a}$, Rodrigo Moreira da Silva ${ }^{b}$, Michel Leandro de Campos ${ }^{c}$, Anelize Bauermeister ${ }^{\mathrm{b}}$, Norberto Peporine \\ Lopes $^{b}$ and Natalia Valadares de Moraes ${ }^{a, *, 10}$ \\ a'Departamento de Fármacos e Medicamentos, Faculdade de Ciências Farmacêuticas, Universidade Estadual Paulista, 14800-903 \\ Araraquara - SP, Brasil \\ bDepartamento de Física e Química, Faculdade de Ciências Farmacêuticas de Ribeirão Preto, Universidade de São Paulo, 14040-903 \\ Ribeirão Preto - SP, Brasil \\ 'Instituto de Ciências da Saúde, Universidade Federal de Mato Grosso, 78550-000 Sinop - MT, Brasil
}

Recebido em 18/11/2020; aceito em 25/01/2021; publicado na web em 24/02/2021

\begin{abstract}
Copalic (CA) and kaurenoic (KA) acids are the main diterpenes found in the oleoresin extracted from the copaiba tree (Copaifera sp). This study aimed to characterize the metabolism of CA and KA in rat and human liver microsomes using liquid chromatography with tandem mass spectrometry (LC-MS/MS). The in vitro assays showed deviations from the Michaelian kinetics in the metabolism of CA and KA. Putative metabolites of CA and KA were characterized by LC-MS/MS using electrospray ionization (ESI) with time of flight (LC-ESI-TOF) and ion-trap (LC-ESI-IT) systems and identified as a CA isomer and 16,17-dihydroxy-kaurenoic acid, respectively. CA and KA are subject to extensive metabolism with each passage through the liver with extraction ratios (E) estimated as 0.97 and 0.99 , respectively. In conclusion, the kinetic parameters and metabolites described here might support drug development and the traditional use.
\end{abstract}

Keywords: metabolism; liver microsomes; copalic acid; kaurenoic acid; Copaifera sp.

\section{INTRODUCTION}

During the colonization of Brazil, Jesuit priests and several naturalists described the use of important indigenous drugs, including jaborandi, ipecac, copaiba, and tobacco. ${ }^{1}$ In the $19^{\text {th }}$ century, the copaiba balsam was one of the most important products of the Amazon region, but production declined in the last two decades, in part due to the absence of scientific investigations to support its use. ${ }^{1,2}$ The copaiba balsam is an oleoresin extracted directly from the copaiba tree's trunk. It is widely used in traditional medicine in Brazil as an anti-inflammatory, wound-healing, antibiotic, and fungicidal drug. ${ }^{2-7}$ Several chemical investigations reported a mixture of biological active sesquiterpenes and diterpenes in copaiba oleoresin. $\beta$-Caryophyllene is the sesquiterpene with the highest occurrence and copalic (CA) and kaurenoic (KA) acids were considered the most important biomarkers for the Copaifera genus. ${ }^{8}$ However, the absorption, distribution, metabolism, and excretion (ADME) processes related to the pharmacokinetics of the active sesquiterpenes, CA, and KA were poorly investigated.

Describing the ADME processes of active compounds is an essential step in the development of phytopharmaceuticals. Knowledge in pharmacokinetics is fundamental to increase the number of biodiversity-based products in the market since it enables predicting therapeutic dose regimens to maximize pharmacological efficacy and avoid toxic effects. ${ }^{9}$ We have recently shown that the intestinal permeability of CA and KA is mainly driven by passive diffusion and is not limited by p-glycoprotein. However, the oral administration of $\mathrm{CA}$ and KA requires enteric-coated formulations due to the chemical instability of these compounds in the stomach $\mathrm{pH} .{ }^{10}$ The present investigation reports, for the first time, the in vitro metabolism of KA and $\mathrm{CA}$ in human and rat liver microsomes. The aim was to predict in vivo metabolism and identify putative metabolites by comparing with previous data using biomimetic models. ${ }^{11}$

\section{EXPERIMENTAL}

\section{Chemicals and reagents}

Copalic acid (CA) and kaurenoic acid (KA) were isolated from commercial samples of copaiba oil (Copaifera langsdorffii) obtained from a cooperative center (Rio Branco, AC, Brazil), as previously described. ${ }^{2}$ The chemical identification was confirmed by NMR and gas-chromatography-mass spectrometry (GC-MS), as also described in a previous study. ${ }^{10}$ Reduced $\beta$-nicotinamide adenine dinucleotide phosphate (NADPH), $\mathrm{MgCl}_{2}$, diclofenac sodium, and fluvastatin sodium ( $\geq 98 \%$ purity) were purchased from SigmaAldrich (Sigma-Aldrich, São Paulo, Brazil). Methyl tert-butyl ether was obtained from Panreac (Panreac, Darmstadt, Germany). Pools of rat liver microsomes (lot RT0541-A, RTMC-PL) and human liver microsomes (20 donors, lot PL039B-C, HMMC-PM) were obtained from Life Technologies (Life Technologies, Itapevi, Brazil). The water used for all enzyme assays was purified by a Milli-Q system (Millipore).

\section{Human plasma}

The clinical protocol for blood donation was approved by the Research Ethics Committee (CEP) of the School of Pharmaceutical Sciences of Araraquara - UNESP (CAAE 65707517.6.0000.5426). Human blood was collected from six participants at the Hemonúcleo Regional de Araraquara "Professora Doutora Clara Pechmann Mendonça" (HN). The inclusion criteria were healthy volunteers aged between 18 and 60 years and weight over $50 \mathrm{~kg}$. The exclusion criteria were pregnant or breastfeeding women and/or participants receiving any pharmacological treatment. After centrifugation of the blood bags, plasma was used for research and other components were donated according to the local protocol for blood donation. 


\section{Preparation of rat (RLM) and human liver microsomes (HLM)}

Pools of RLM and HLM, at the concentration of $20 \mathrm{mg}$ of proteins $/ \mathrm{mL}$, were kept at $-80{ }^{\circ} \mathrm{C}$ until the time of the experiment. The microsomes were thawed only on the day of the experiment,

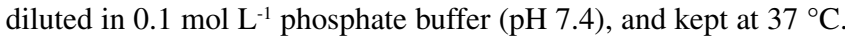
The incubation medium with liver microsomes consisted of $490 \mu \mathrm{L}$ of $0.1 \mathrm{~mol} \mathrm{~L}^{-1}$ phosphate buffer ( $\left.\mathrm{pH} 7.4\right)$, containing $4 \mathrm{mmol} \mathrm{L}^{-1} \mathrm{NADPH}$ and $6 \mathrm{mmol} \mathrm{L}^{-1} \mathrm{MgCl}_{2}$ and $500 \mu \mathrm{L}$ of RLM or HLM solutions.

\section{Fraction unbound $\left(F_{u}\right)$ in plasma and liver microsomes}

Stock solutions of CA and KA were prepared in dimethyl sulfoxide (DMSO). The final DMSO maximum concentration in the incubation medium was $0.1 \%$. The $\mathrm{Fu}$ in the plasma $\left(\mathrm{F}_{\mathrm{u}, \mathrm{p}}\right)$ and microsomal incubation media $\left(\mathrm{F}_{\mathrm{u}, \mathrm{mic}}\right)$ was determined by ultracentrifugation. ${ }^{12}$ Human plasma $(10 \mathrm{~mL})$ or microsomal incubation medium $(10 \mathrm{~mL})$ were spiked with $\mathrm{CA}$ or $\mathrm{KA}$ in concentrations of 2,50 , and $100 \mu \mathrm{mol} \mathrm{L} \mathrm{L}^{-1}$ and incubated for 30 minutes at $37^{\circ} \mathrm{C}$, in triplicates. The samples were transferred to appropriate tubes (Beckman Coulter Ultra-Clear) and centrifuged for 24 hours at $37^{\circ} \mathrm{C}$ and $100,000 \times \mathrm{g}$ (Beckman Coulter Optima L 90K Ultracentrifuge, United States). Aliquots of $100 \mu \mathrm{L}$ of plasma or microsomal medium samples were collected before ultracentrifugation to determine the total concentration. After ultracentrifugation, samples of $100 \mu \mathrm{L}$ of the middle plasma layer were collected to determine the unbound drug concentration in the plasma. Samples of $100 \mu \mathrm{L}$ of the supernatant from the microsomal medium were collected for the determination of the unbound drug concentration in the microsomes. All samples were processed and analysed using liquid chromatography-mass spectrometry (LC-MS) analysis. The $\mathrm{F}_{\mathrm{u}, \mathrm{p}}$ and $\mathrm{F}_{\mathrm{u}, \mathrm{mic}}$ values were determined using equations 1 and 2 :

$$
\begin{aligned}
& F_{u, p}=\frac{\text { Unbound drug concentration in plasma }}{\text { Total drug concentration in plasma }} \\
& F_{u, m i c}=\frac{\text { Unbound drug concentration in microsomal medium }}{\text { Total drug concentration in microsomal medium }}
\end{aligned}
$$

\section{In vitro metabolism in rat and human liver microsomes}

\section{Kinetic assays in RLM and HLM}

Incubations were performed in triplicates on 12-well plates (Greiner bio-one, Kremsmünster, Austria) and the incubation medium had a total volume of $1 \mathrm{~mL}$. Solutions of CA or KA in $0.1 \mathrm{~mol} \mathrm{~L}^{-1}$ phosphate buffer containing $2 \mathrm{mmol} \mathrm{L}^{-1} \mathrm{NADPH}$ and $3 \mathrm{mmol} \mathrm{L}^{-1}$ $\mathrm{MgCl}_{2}$ were kept at $37^{\circ} \mathrm{C}$ with agitation at $100 \mathrm{rpm}$ (Ethik Technology model 430 - RDB T5, São Paulo, Brazil) for 5 minutes before incubation. Incubation medium for metabolism assays consisted of $10 \mu \mathrm{L}$ of the substrates $\mathrm{CA}$ or KA in varying concentrations; $490 \mu \mathrm{L}$ of $0.1 \mathrm{~mol} \mathrm{~L}^{-1}$ phosphate buffer ( $\mathrm{pH} 7.4$ ), containing $4 \mathrm{mmol} \mathrm{L}^{-1} \mathrm{NADPH}$ ( $\beta$-nicotinamide and adenine dinucleotide phosphate) (SigmaAldrich; São Paulo, SP, Brazil) and $6 \mathrm{mmol} \mathrm{L}^{-1}$ magnesium chloride $\left(\mathrm{MgCl}_{2}\right)$ (Sigma-Aldrich, São Paulo, Brazil); and $500 \mu \mathrm{L}$ of RLM or HLM solutions. The following incubation conditions were optimized: a) the concentration of microsomal protein in RLM or HLM: 0.05, 0.1 , and $0.5 \mathrm{mg}$ of proteins $/ \mathrm{mL}$ of incubation medium; b) presence or absence of the cofactor $2 \mathrm{mmol} \mathrm{L}^{-1} \mathrm{NADPH}$; c) incubation times: 0-90 minutes; d) final substrate concentration: from 0.1-300 $\mu \mathrm{mol} \mathrm{L} \mathrm{L}^{-1}$. The experiments were initially carried out with the RLM. Assays using HLM were designed based on the results found for RLM.

After 5 minutes of preincubation at $37{ }^{\circ} \mathrm{C}$, the reaction was initiated with the addition of microsomal proteins (RLM or HLM).
Aliquots of $100 \mu \mathrm{L}$ were collected at different times and the reaction was terminated by adding $1 \mathrm{~mL}$ of methyl tert-butyl ether solvent containing $50 \mu \mathrm{L}$ of $2.4 \mu \mathrm{mol} \mathrm{L}-1$ fluvastatin as the internal standard (purity: $\geq 98 \%$; Sigma-Aldrich, St. Louis, MO, USA). Positive control incubations containing $0.4 \mu \mathrm{mol} \mathrm{L}{ }^{-1}$ diclofenac (purity: $\geq 98 \%$, SigmaAldrich, São Paulo, Brazil) were conducted since its metabolism in microsomes has been well described in the literature. ${ }^{13}$

The resulting content of reactions were agitated for 15 minutes in a horizontal reciprocating shaker (TE-240 Tecnal at $130 \pm 10 \mathrm{cycles} / \mathrm{min}$, Piracicaba, Brazil) and centrifuged for 10 minutes at $15.000 \times \mathrm{g}$, $5{ }^{\circ} \mathrm{C}$. An aliquot of $900 \mu \mathrm{L}$ of the organic phase was transferred to $1.5 \mathrm{~mL}$ microtubes and evaporated to dryness at $40{ }^{\circ} \mathrm{C}$ (Genevac ${ }^{\mathrm{TM}}$ Centrifugal Duo, Ipswich UK). The dried contents were reconstituted in $90 \mu \mathrm{L}$ of the mobile phase described below and $20 \mu \mathrm{L}$ were injected into the chromatographic system.

\section{LC-MS analysis}

The LC-MS analysis was performed using the Perkin Elmer chromatographic system (Perkin Elmer, Shelton, USA), as reported in previous studies. ${ }^{10}$ In summary, CA, KA, and the internal standard fluvastatin were resolved on a reversed-phase Poroshell 120 EC-C18 end-capped column $(100 \times 4.6 \mathrm{~mm}, 2.7 \mu \mathrm{m}$, Agilent Technologies, Santa Clara, United States), kept at $22{ }^{\circ} \mathrm{C}$. The mobile phase consisted of acetonitrile: $5 \mathrm{mmol} \mathrm{L}-1$ ammonium acetate solution $(\mathrm{pH}=4)$ $(90: 10, \mathrm{v} / \mathrm{v})$, in isocratic mode, at a flow rate of $0.5 \mathrm{~mL} / \mathrm{min}$. The mass spectrometry detection was performed on negative ionization mode. The capillary voltage in the electrospray ionization interface was $6.0 \mathrm{kV}$. The desolvation temperature was maintained at $350{ }^{\circ} \mathrm{C}$. Nitrogen was used as the nebulizer gas $(12 \mathrm{~L} / \mathrm{min})$. The CA, KA, and the internal standard were monitored by their respective mass-tocharge ratios $(\mathrm{m} / \mathrm{z}) 303,301$, and $410\left([\mathrm{M}-\mathrm{H}]^{-}\right)$using single reaction monitoring. The areas of peaks were used as quantitative information regarding the compounds.

Diclofenac, used as a probe substrate, was analyzed by LC-MS using the reversed-phase Poroshell 120 EC-C18 end-capped column $(100 \times 4.6 \mathrm{~mm}, 2.7 \mu \mathrm{m}$, Agilent Technologies, Santa Clara, United States). The mobile phase consisted of acetonitrile: $0.1 \%$ formic acid (60:40, v/v), in isocratic mode, at a flow rate of $0.5 \mathrm{~mL} \mathrm{~min}^{-1}$. Mass spectrometry detection was carried out on positive ion mode. Nitrogen was used as the nebulizer gas $(12 \mathrm{~L} / \mathrm{min})$, and the capillary voltage in the electrospray ionization interface was $6.0 \mathrm{kV}$. Desolvation temperature was set at $350{ }^{\circ} \mathrm{C}$. The $[\mathrm{M}+\mathrm{H}]^{+}$ion with $\mathrm{m} / \mathrm{z} 296$ was used to monitor diclofenac.

\section{Data analysis}

Substrate concentrations in the depletion assays were used to assess the kinetic parameters using the maximum rate of reaction. The Michaelis-Menten model and deviations from the classical hyperbola were tested using nonlinear fitting in GraphPad Prism (version 8.3.0, San Diego, CA, USA). The Eadie-Hofstee plot $\left(\mathrm{V}_{0} / \mathrm{S}\right.$ on the $\mathrm{x}$-axis and $\mathrm{V}_{0}$ on the $\mathrm{y}$-axis) and clearance plots were used to diagnose deviations from the classic Michaelis-Menten model. In vitro metabolism of CA and KA in RLM and HLM fitted to the Hill equation (3):

$$
v=\frac{\mathrm{V}_{\max } \cdot[\mathrm{S}]^{h}}{\mathrm{~S}_{50}^{h}+[\mathrm{S}]^{h}}
$$

where $v$ is the initial rate of the reaction; $\mathrm{V}_{\max }$ is the maximum velocity; [S] is the substrate concentration; $S_{50}$ is the concentration of the substrate in which the rate of reaction is half the maximum rate $\left(\mathrm{V}_{\max }\right)$, indicating the "apparent affinity" between enzyme and substrate; and $h$ is the Hill coefficient, which shows the degree of cooperativity of the substrate bound to the enzyme. ${ }^{14}$ The maximum 
intrinsic clearance $\left(\mathrm{CL}_{\max }\right)$, which represents the maximum clearance resulting from self-activation, ${ }^{15}$ was calculated by equation 4 :

$$
\mathrm{CL}_{\max }=\frac{\mathrm{V}_{\max }}{\mathrm{S}_{50}} \times \frac{(h-1)}{h(h-1)^{\frac{1}{h}}}
$$

In vitro-in vivo extrapolation (IVIVE)

The extrapolation of the in vivo hepatic clearance of CA and KA from in vitro clearance (Eq. 5) accounted for the microsomal protein content (in milligrams) in relation to the liver weight (in grams) and the liver weight (in grams) in relation to the body weight (in $\mathrm{kg}$ ). The microsomal protein content was set at $45.0 \mathrm{mg}$ per gram of human liver. The escalating factor of $20.0 \mathrm{~g}$ liver weight $/ \mathrm{kg}$ body weight was used. ${ }^{16}$

$\mathrm{CL}_{\text {int }}^{\prime}=\mathrm{CL}_{\max } \times \frac{\mathrm{mg} \text { of microsomal protein }}{\mathrm{g} \text { of liver weight }} \times \frac{\mathrm{g} \text { of liver weight }}{\mathrm{kg} \text { of body weight }}$

The well-stirred model was used to estimate hepatic plasma clearance $\left(\mathrm{Cl}_{\mathrm{H}}\right) \cdot{ }^{17}$ This model assumes that the distribution of the drug in the liver is limited by perfusion and occurs instantly and homogeneously, as seen in equation 6 :

$$
\mathrm{Cl}_{\mathrm{H}}=\frac{\mathrm{Q}_{\mathrm{H}, \mathrm{B}} \times f \mathrm{u} \times \mathrm{CLu}_{\mathrm{int}, \mathrm{H}}}{\mathrm{Q}_{\mathrm{H}, \mathrm{B}}+f \mathrm{u} \times \mathrm{CLu}_{\mathrm{int}, \mathrm{H}}}
$$

where $\mathrm{Q}_{\mathrm{H}, \mathrm{B}}$ is the hepatic blood flow $\left(20 \mathrm{~mL} \mathrm{~min}^{-1} \mathrm{~kg}^{-1}\right)$; $\mathrm{F}_{\mathrm{u}}$ is the fraction unbound in plasma; and $\mathrm{CLu}_{\mathrm{int}, \mathrm{H}}$ is the intrinsic clearance scaled from in vitro data (Eq. 5) and corrected by the free fraction in the microsomal system $\left(\mathrm{F}_{\mathrm{u}, \mathrm{mic}}\right)$, according to equation 7 :

$$
\mathrm{CLu}_{\text {int }, \mathrm{H}}=\frac{\mathrm{CL}_{\text {int }, \mathrm{H}}}{\mathrm{F}_{\mathrm{u}, \mathrm{mic}}}
$$

The rate of drug extraction by the liver $(\mathrm{E})$ was estimated by the $\mathrm{CL}_{\mathrm{H}} / \mathrm{Q}_{\mathrm{H}, \mathrm{B}}$ ratio. Drugs with an extraction rate below 0.3 are considered to have a low extraction rate and drugs with values above 0.7 indicate a high rate of extraction through the liver. ${ }^{18}$ The hepatic extraction ratio is useful to evaluate the impact of the contributors to drug hepatic clearance, such as the fraction unbound, the liver blood flow, or the intrinsic clearance.

\section{Metabolite identification}

\section{Depletion assay and sample preparation}

An in vitro metabolism assay using RLM or HLM was performed for CA and KA in high concentrations $\left(300 \mu \mathrm{mol} \mathrm{L} \mathrm{L}^{-1}\right)$ as substrates. Samples were collected after 10 and 20 minutes of incubation for human microsomes and after 20 and 30 minutes for rat microsomes, for KA and CA, respectively. The collected samples were prepared by liquid-liquid extraction using ethyl acetate (Caledon Laboratories, Ontario, Canada), agitated on a reciprocating table for 20 minutes, and centrifugated at $15,000 \times \mathrm{g}$ for 10 minutes at $5{ }^{\circ} \mathrm{C}$. The organic phases from 5 replicates were combined in a single pool, evaporated to dryness at $40{ }^{\circ} \mathrm{C}$ and reconstituted in the mobile phase [acetonitrile:water (10:90, v/v) acidified with $0.1 \%$ formic acid]. Control samples (containing only CA or KA) and blank samples (containing only the RLM or HLM), both in $0.1 \mathrm{~mol} \mathrm{~L}^{-1}$ phosphate saline buffer (PBS), were prepared using the same conditions.

\section{Analysis by low- and high-resolution mass spectrometry}

The chromatography step before the low- or high-resolution mass spectrometry analyses were performed in a Shimadzu liquid chromatography system model LC-20AD (Kyoto, Japan), DGU-20A degasser, SIL-20AHT auto-sampler, SPD-M20A diode array detector (200-600 nm), CTO column oven -20A and CBM-20A communication module. The samples were injected on a C18 Luna chromatographic column (Phenomenex, $5 \mu \mathrm{m}, 250 \times 4.6 \mathrm{~mm}$ ). The mobile phase consisted of acetonitrile and water acidified with formic acid $0.1 \%(10: 90, \mathrm{v} / \mathrm{v})$ and the flow rate was set at $0.5 \mathrm{~mL} / \mathrm{min}$.

The sequential mass spectrometry analysis, at low resolution, was performed in an AmaZon SL mass spectrometer (Bruker Daltonics, Massachusetts, USA) equipped with an electrospray ionization (ESI) source and an ion trap (IT) analyzer. Spectra were acquired in the negative ionization mode (ESI-), with a capillary voltage of $3.5 \mathrm{kV}$. The nebulization gas used was nitrogen $\left(\mathrm{N}_{2}\right)$, with a drying temperature of $300{ }^{\circ} \mathrm{C}$, flow rate of $9 \mathrm{~L} / \mathrm{min}$, and pressure of $40 \mathrm{psi}$. $\mathrm{N}_{2}$ was used as the collision gas for fragmentation. Data acquisition and analysis were performed using the Bruker Compass Data Analysis 4.3 software.

The high-resolution data were acquired in a micrOTOF - Q II mass spectrometer (Bruker Daltonics, Massachusetts, USA) equipped with an electrospray ionization source and a time-of-flight analyzer. The capillary and end-plate voltage in the electrospray source was $3.5 \mathrm{kV}$ and $0.5 \mathrm{kV}$, respectively, in negative ionization mode, with a drying gas temperature $\left(\mathrm{N}_{2}\right)$ of $180{ }^{\circ} \mathrm{C}$, flow rate of $4 \mathrm{~L} / \mathrm{min}$, and pressure of 0.4 bar. A solution of sodium trifluoroacetic acid (Na-TFA), at a concentration of $10 \mathrm{mg} / \mathrm{mL}$, was used for equipment calibration. For data acquisition and analysis, the Bruker Compass Data Analysis 4.1 software (Bremen, Germany) was used.

\section{RESULTS AND DISCUSSION}

\section{Binding to plasma and liver microsomes}

In pharmacometrics, the fraction unbound in the plasma is considered a fundamental pharmacokinetic parameter. It influences the processes of drug distribution, transport mediated by drug transporters, excretion, and the pharmacological or toxicological effect itself. ${ }^{19} \mathrm{~F}_{\mathrm{u}, \mathrm{p}}$ can be used in different applications, such as in the interpretation of plasma concentrations that are effectively associated with the pharmacological effect or in the in vitro-in vivo extrapolation (IVIVE) of metabolism and/or transport studies. ${ }^{19}$

The initial evaluation of plasma protein binding was performed by ultrafiltration. Our results suggested high non-specific binding to the device, probably due to the high lipophilicity of both CA and KA. ${ }^{10}$ The treatment of the membranes with $5 \%$ Tween 80 (Synth, Diadema, Brazil) or a washing step with phosphate buffer ${ }^{20}$ was not enough to avoid non-specific binding to the ultrafiltration device.

Using the ultracentrifugation technique, unbound concentrations of CA and KA to plasma proteins and microsomal liver proteins were successfully determined (Table 1). Ultracentrifugation is superior to ultrafiltration to determine unbound concentration for lipophilic drugs due to the absence of non-specific adsorption on the filtration membrane. ${ }^{12}$ The plasma protein binding assay was performed using different drug concentrations to assess whether the protein binding is linear. ${ }^{21}$ Clinically, saturation in drug binding to plasma proteins or tissue proteins may not occur due to a high binding capacity or low binding affinity. In this case, protein binding is considered linear and, therefore, independent of the total concentration of the drug. Saturation in protein binding can be observed for a few examples. In these cases, binding to proteins is concentration-dependent and considered nonlinear. ${ }^{21}$

The binding of KA to plasma proteins was lower when compared to CA. $F_{u, p}$ ranged from $0.82-0.98$ for KA and $0.47-0.53$ for CA. The calculation of the free fraction of KA, as shown in Table 1, was 
Table 1. Fraction unbound of the CA and KA in plasma $\left(\mathrm{F}_{\mathrm{u}, \mathrm{p}}\right)$ and in hepatic microsomal incubation media $\left(\mathrm{F}_{\mathrm{u}, \mathrm{mic}}\right)$. Data presented as mean [coefficient of variation $(\%), \mathrm{n}=6]$

\begin{tabular}{|c|c|c|}
\hline & $\mathrm{F}_{\mathrm{u}, \mathrm{p}}$ & $\mathrm{F}_{\mathrm{u}, \text { mic }}$ \\
\hline \multicolumn{3}{|l|}{ Copalic acid } \\
\hline $2 \mu \mathrm{mol} \mathrm{L}-1$ & $0.47(14.8 \%)$ & $0.27(10.3 \%)$ \\
\hline $50 \mu \mathrm{mol} \mathrm{L}-1$ & $0.53(19.2 \%)$ & $0.21(8.6 \%)$ \\
\hline $100 \mu \mathrm{mol} \mathrm{L}-1$ & $0.53(19.8 \%)$ & $0.26(12.8 \%)$ \\
\hline \multicolumn{3}{|l|}{ Kaurenoic acid } \\
\hline $2 \mu \mathrm{mol} \mathrm{L}{ }^{-1}$ & $0.82(11.5 \%)$ & $0.59(17.3 \%)$ \\
\hline $50 \mu \mathrm{mol} \mathrm{L}{ }^{-1}$ & $0.97(8.72 \%)$ & $0.31(22.3 \%)$ \\
\hline $100 \mu \mathrm{mol} \mathrm{L}-1$ & $0.98(5.6 \%)$ & $0.21(30.0 \%)$ \\
\hline
\end{tabular}

normalized by an instability factor for KA, since it was considered unstable in the plasma after 24 hours of incubation. In human plasma, KA can be considered stable for 12 hours. ${ }^{10}$

The quantitative structure/activity relationship (QSAR) models for free fraction predictions in microsomal incubations have low accuracy for compounds with high lipophilicity, ${ }^{22}$ such as CA and KA. In this study, the mean $\mathrm{F}_{\mathrm{u} \text {,mic }}$ of the CA was approximately 0.25 in the concentration range of 2 to $100 \mu \mathrm{mol} \mathrm{L}^{-1}$ (Table 1). It is usually expected increasing fraction unbound with increasing total drug concentration in a typical nonlinear protein binding due to saturation of protein binding sites. However, for KA, increasing drug total concentrations resulted in reduced fraction unbound in microsomes, suggesting atypical non-linear binding to microsomal proteins. Examples for the atypical nonlinear protein binding had been recently discussed by Deitchman et al. ${ }^{21}$ Tetracyclines represent a class of drugs with atypical non-linear binding to plasma proteins, since the free fraction decreases with increasing concentrations. For tigecycline, a U-shaped curve was observed, representing a mixture of the typical and atypical profile in binding to plasma proteins. ${ }^{21}$

\section{In vitro metabolism in liver microsomes}

Initial enzyme reactions were conducted evaluating $0.05,0.1$, and $0.5 \mathrm{mg}$ of microsomal proteins $/ \mathrm{mL}(\mathrm{n}=3)$ and a final substrate concentration of $0.5 \mu \mathrm{mol} \mathrm{L} \mathrm{L}^{-1}$. Based on the observed depletion, microsomal protein concentrations equivalent to $0.1 \mathrm{mg} \mathrm{mL}^{-1}$ and $0.05 \mathrm{mg} \mathrm{mL}^{-1}$ were selected for further assays using CA and KA as substrates, respectively. The addition of the cofactor NADPH resulted in a significant depletion of substrates, suggesting that $\mathrm{CA}$ and KA metabolisms are mediated by P450 enzymes (CYP), which is an NADPH-dependent system. The plots of velocity of reaction and substrate concentration revealed a non-hyperbolic association that suggests a deviation from the Michaelis-Menten enzyme model (Figures 1 and 2). Eadie-Hofstee plots were used as a diagnosis to distinguish Michaelis-Menten kinetics from atypical enzymatic kinetics. When the enzymatic kinetics follows the Michaelis-Menten model, a line is observed in the Eadie-Hofstee plot. The results observed here suggested that the Hill equation was the most adequate to describe the metabolism of CA and KA in both rat and human liver microsomes (Figures 1 and 2). The observation of Hill coefficients $>1$ for both RLM and HLM suggests positive cooperative binding which means that once one ligand is bound to the enzyme, its affinity for other ligand molecules increases (Table 2). The metabolism of KA did not reach saturation in HLM within the range of concentrations evaluated. Considering that the solubility of KA limited the evaluation of higher concentrations, the kinetic parameters could not be precisely estimated for KA in HLM.

The estimated parameters for $\mathrm{CA}$ and KA were presented in Table 2, which shows that the $\mathrm{V}_{\max }$ for CA in RLM and HLM are within the same order of magnitude. Using RLM, the $\mathrm{V}_{\max }$ for KA was lower than that of CA (Table 2). The parameter $S_{50}$ represents the concentration of the substrate for which the enzyme is hemisaturated. The $\mathrm{S}_{50}$ for CA was $7.8 \mu \mathrm{mol} \mathrm{L}^{-1}$ and $45.2 \mu \mathrm{mol} \mathrm{L}^{-1}$ for RLM and HLM, respectively. For KA, the $S_{50}$ was 32.2 and $63.9 \mu \mathrm{mol} \mathrm{L} \mathrm{L}^{-1}$ in RLM and HLM, respectively, suggesting that both CA and KA showed a higher apparent affinity with the rat microsomes.
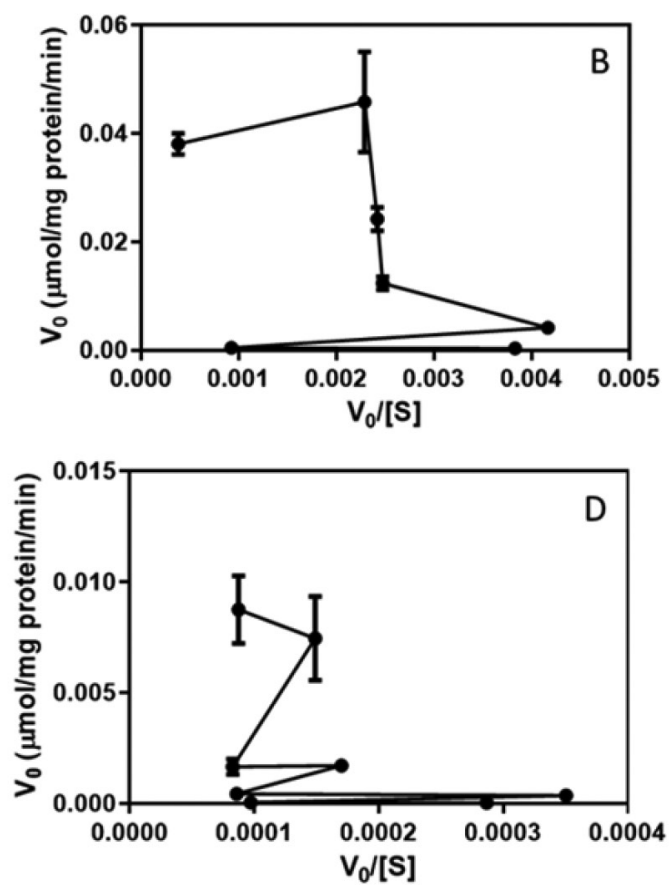

Figure 1. In vitro metabolism of copalic acid (CA) in A and B and kaurenoic acid (KA) in C and D using rat liver microsomes $(n=3)$. A and C: plots of velocity of reaction versus substrate concentration; $B$ and D: Eadie Hofstee plots of v versus v/[S] 

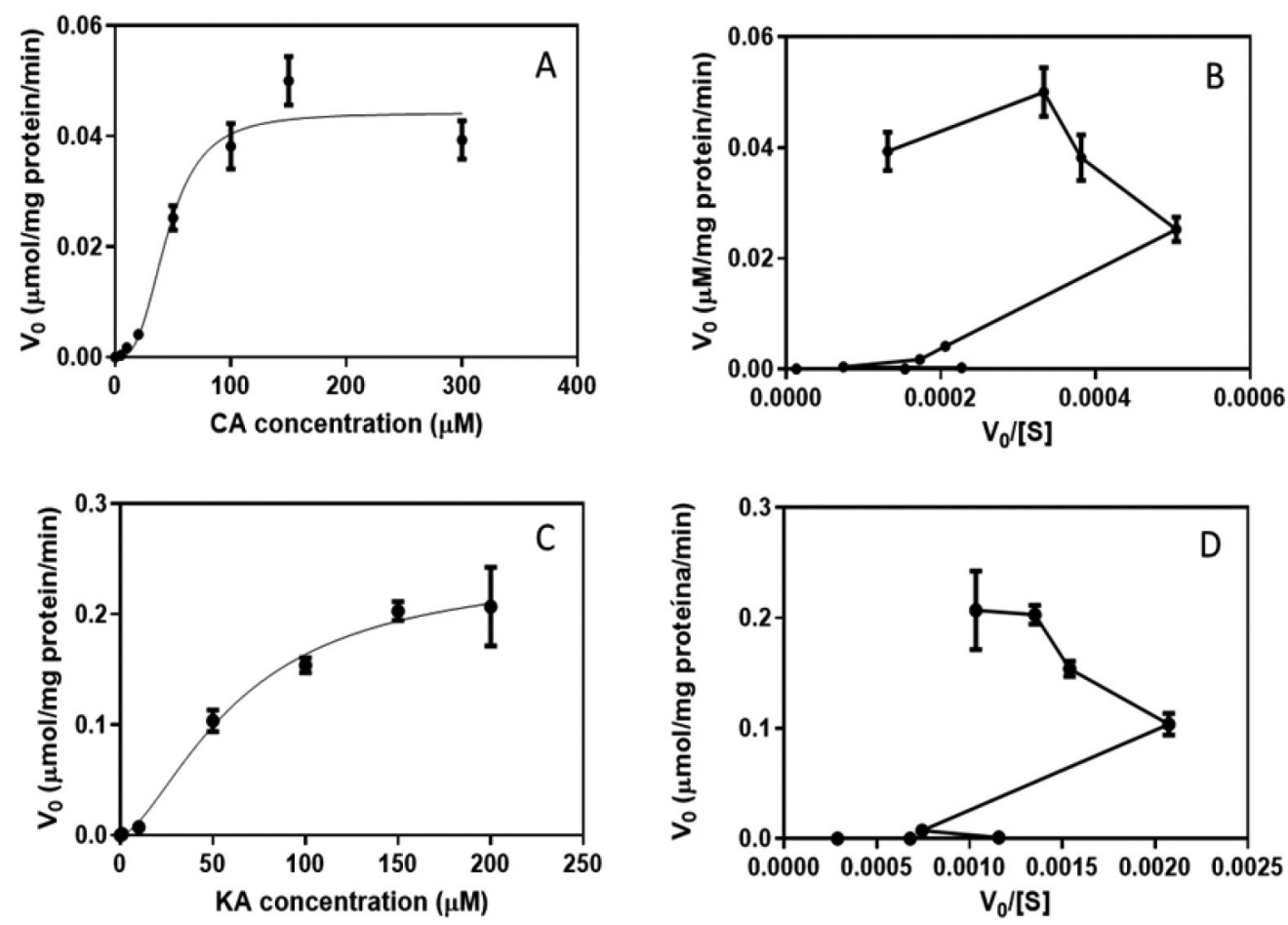

Figure 2. In vitro metabolism of copalic acid (CA) in $A$ and $B$ and kaurenoic acid $(K A)$ in $C$ and $D$ using human liver microsomes $(n=3)$. A and C: plots of velocity of reaction versus substrate concentration; $B$ and $D$ : Eadie Hofstee plots of $v$ versus $v /[S]$

Table 2. Kinetic parameters of in vitro metabolism of copalic acid (CA) and kaurenic acid (KA) in rat (RLM) and human (HLM) hepatic microsomes using Hill's equation. Data presented as mean (IC 95\%), $\mathrm{n}=3$

\begin{tabular}{|c|c|c|c|c|c|c|c|c|}
\hline & \multicolumn{2}{|c|}{$\mathrm{V}_{\max }(\mu \mathrm{mol} / \mathrm{mg}$ protein/min $)$} & \multicolumn{2}{|c|}{$\mathrm{H}$} & \multicolumn{2}{|c|}{$\mathrm{S}_{50}\left(\mu \mathrm{mol} \mathrm{L} \mathrm{L}^{-1}\right)$} & \multirow{2}{*}{$\mathrm{K}_{\text {prime }}$} & \multirow{2}{*}{$\begin{array}{c}\mathrm{CL}_{\max } \\
(\mathrm{mL} / \mathrm{min} / \mathrm{mg} \\
\text { protein })\end{array}$} \\
\hline & Estimated value & IC $95 \%$ & Estimated value & IC $95 \%$ & Estimated value & IC $95 \%$ & & \\
\hline \multicolumn{9}{|c|}{ Copalic acid } \\
\hline RLM & 0.04283 & $0.037-0.049$ & 2.599 & $1.538-4.192$ & 7.8 & $5.9-9.9$ & 208.4 & 2.82 \\
\hline HLM & 0.0442 & $0.040-0.049$ & 2.96 & 1.96-n.d. & 45.2 & $37.1-54.0$ & 78244 & 0.52 \\
\hline \multicolumn{9}{|c|}{ Kaurenoic acid } \\
\hline RLM & 0.0095 & $(0.0073-0.060)$ & 2.343 & $0.7945-8.874$ & 32.2 & $21.9-780.4$ & 3401 & 0.14 \\
\hline HLM & 0.2440 & $0.1938-0.5437$ & 1.587 & $0.8254-3.201$ & 63.9 & $42.6-310.0$ & 733.9 & 1.96 \\
\hline
\end{tabular}

Hill's equation: $V=V_{\max } \times S^{h} /\left(S_{50}^{h}+S^{h}\right)$, where $\mathrm{V}_{\max }=$ maximum rate of the enzymatic reaction $\left(\mathrm{V}_{\max }\right.$ is the velocity of the enzyme extrapolated to very high concentrations of the substrate and therefore it is almost always greater than any velocity evaluated in the experiment); $S_{50}$ is the substrate concentration that produces half the maximum velocity; and $\mathrm{h}=$ Hill coefficient. When $\mathrm{h}=1$, the equation is identical to the Michaelis-Menten equation. When $\mathrm{h}>1.0$, the curve is sigmoidal due to positive cooperation. $\mathrm{K}_{\text {prime }}=$ parameter related to $\mathrm{Km}$. $\mathrm{K}_{\text {prime }}$ is calculated as $S_{50}^{h}$ and expressed in units of concentration.

The phenomenon of self-activation shows a gradual increase in clearance as the concentration of the substrate increases until reaching a maximum value. From this maximum value, a reduction in clearance is observed because of the increase in the substrate concentration due to saturation. This is like what is observed with the Michaelis-Menten kinetics. ${ }^{15}$ Our results have shown that the Hill coefficient was greater than 1 for both CA and KA considering in vitro metabolism assays using liver microsomes. This result confirms the positive cooperativity, which means that the binding of the substrate to the enzymatic site increases the affinity of the enzyme for the binding of another substrate molecule. Hill coefficients greater than 1 are common for substrates of CYP3A $4,{ }^{23}$ but atypical enzymatic kinetics have also been observed for CYP2C9 and CYP2B6 substrates. ${ }^{24}$ CYP3A4 is expressed mainly in the human liver and intestine. It metabolizes compounds with a wide diversity of chemical characteristics and is responsible for the metabolism of a vast number of xenobiotics and drugs available in clinical practice. ${ }^{23}$

Due to the deviation from the Michaelis-Menten model, the maximum intrinsic clearance $\left(\mathrm{CL}_{\max }\right)$ was determined in place of the intrinsic clearance $\left(\mathrm{CL}_{\text {int }}\right)$, as demonstrated by Houston and Kenworthy. ${ }^{15} \mathrm{CL}_{\max }$ is an estimate of clearance when the enzyme is fully activated, and saturation has not occurred. ${ }^{25} \mathrm{The}^{\mathrm{CL}_{\max }}$ for $\mathrm{CA}$ in RLM was approximately 5 times greater than the value observed for HLM. Higher interspecies variability was observed for KA, with a $\mathrm{CL}_{\max } 14$ times higher in HLM when compared to RLM. The $\mathrm{CL}_{\max }$ was further used to predict in vivo hepatic clearance in humans.

\section{In vitro-in vivo extrapolation for hepatic clearance}

The ability to predict human liver clearance represents an important advance in precision medicine, as it helps predict therapeutic doses and systemic exposure to achieve the desired effect and minimize signs of toxicity. The kinetic data of enzyme reactions observed in vitro were used to predict the in vivo clearance using the well-stirred liver model. ${ }^{17}$ The intrinsic clearance values were scaled up considering microsomal protein content and liver mass. The rate of drug extraction by the liver (E) showed values close to the unit for both diterpenes evaluated here (Table 3). CA and KA 
were then classified as drugs with a high extraction ratio. This data indicates that during each passage through the liver, CA and KA are almost completely cleared. It also suggests that the clearance is flow-dependent and variations in the hepatic blood flow can impact the hepatic clearance CA and KA. Variations in the plasma protein binding or in the intrinsic clearance will have a smaller impact on total hepatic clearance.

Table 3. In vivo-in vitro extrapolation of enzyme metabolism of copalic and kaurenoic acids using human liver microsomes (HLM)

\begin{tabular}{lcc}
\hline & $\mathrm{CL}_{\mathrm{H}}(\mathrm{mL} / \mathrm{min} / \mathrm{kg})$ & $\mathrm{E}$ \\
\hline Copalic acid, HLM & 19.5 & 0.97 \\
Kaurenoic acid, HLM & 19.8 & 0.99 \\
\hline
\end{tabular}

$\mathrm{CL}_{\mathrm{H}}$ : hepatic clearance; $\mathrm{E}$ : extraction ratio.

\section{Identification of metabolites}

Usually, the GC-MS is a more common technique for copaiba terpenoids analysis. ${ }^{8}$ On the other hand, recent studies on ESI-MS/ MS fragmentation of isopimarane and labdane-type acid diterpenes open the perspective to work with LC-MS protocols. ${ }^{26,27}$ The LCESI-TOF analysis has shown a peak with a retention time of 3.3 minutes as a potential metabolite of KA in both RLM and HLM. As shown in Figure 3 (A-C), no peaks at 3.3 minutes were found in the blank sample (containing only RLM) or in the control sample (containing only KA). The mass spectrum referring to this peak showed an intense ion with $\mathrm{m} / \mathrm{z} 335.2225$ (Figure 4). Previous KA biomimetic metabolism studies employing metalloporphyrins have shown the formation of a KA di-hydroxylated metabolite as the major reaction product, identified as 16,17-dihydroxy-kaurenoic acid. ${ }^{11}$ The microsomal model employed in this work corroborate the KA biomimetic metabolism and the di-hydroxylated metabolite was
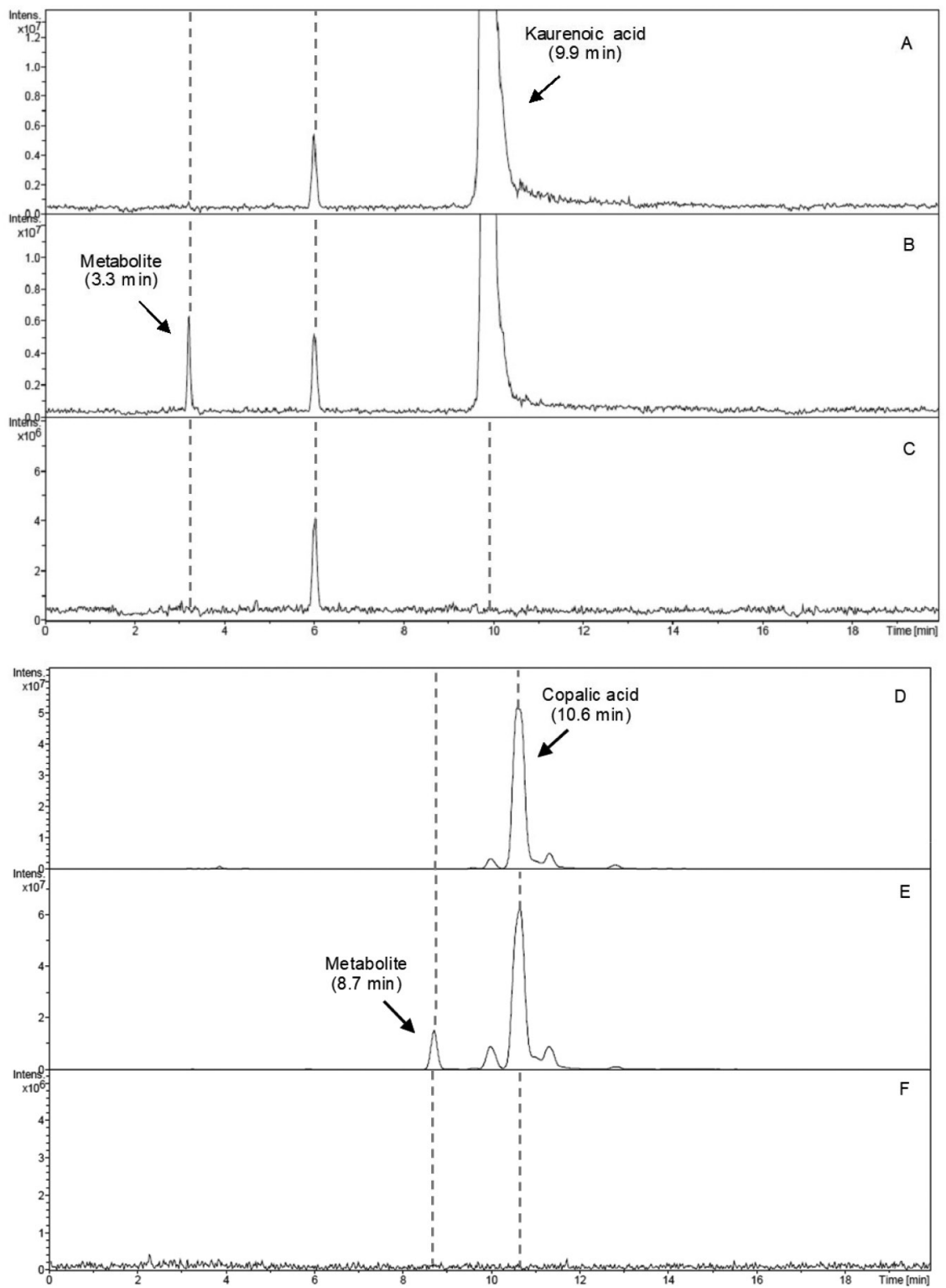

Figure 3. Extracted ion chromatograms of in vitro metabolism samples with rat liver microsomes (RLM) showing (A) kaurenoic acid ( $/ 2 / z 301$, retention time $9.9 \mathrm{~min}$ ) incubated without RLM (control sample); (B) kaurenoic acid metabolite ( $\mathrm{m} / \mathrm{z} 335$, retention time $3.3 \mathrm{~min}$ ) after incubation with HLM; (C) blank sample showing the occurrence of the unknow signal at the mobile phase; (D) copalic acid (retention time 10.6 min) incubated without RLM (control sample), (E) copalic acid metabolite (retention time 8.7 min) after incubation with RLM and (F) blank sample. All samples were prepared by liquid-liquid extraction using ethyl acetate and analysed by LC-ESI-MS in negative ion mode 

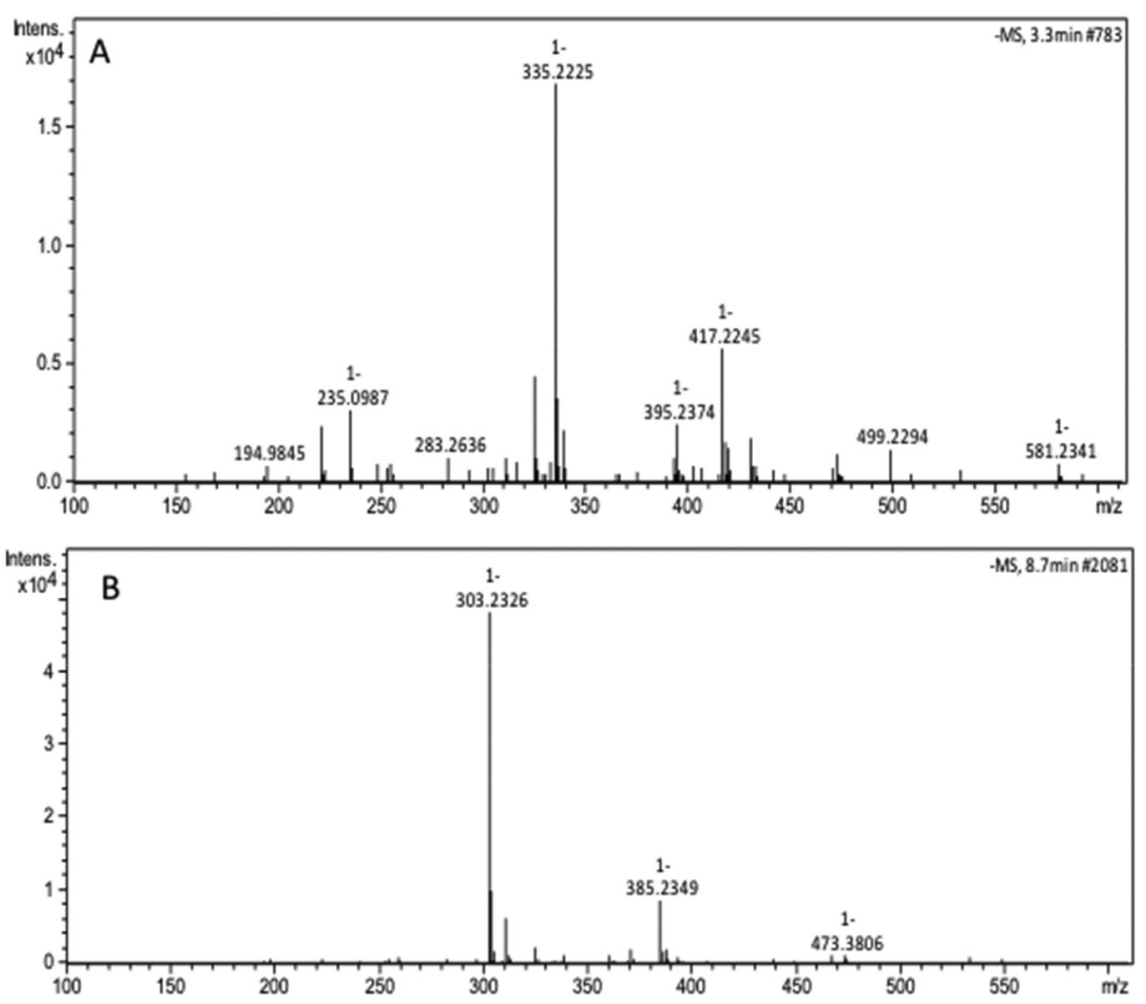

Figure 4. Mass spectrum of the metabolism product of (A) KA and (B) CA in RLM, obtained by LC-ESI-TOF analysis

confirmed by mass spectrometry high resolution analysis (Table 4).

The LC-ESI-TOF analysis of in vitro CA metabolism by RLM suggested that the peak with retention time of 8.7 minutes could be a potential metabolite, since it was not observed in the blank or control samples (Figure 3, D-F). The same ion was also observed after CA metabolism by HLM. The mass spectrum for this metabolite in RLM showed an ion of greater intensity with $\mathrm{m} / z, 303.2326$ in the negative mode of ionization [M-H], which has the same mass as CA (Table 4) and suggests an isomerization reaction. Aguiar and co-workers ${ }^{27}$ showed the possible major fragmentation reactions of CA and in the present study we observed the same ions values (Figures 5 and 6.1). The ion structures proposed by Aguiar and co-workers were supported by computational chemistry and the fragmentation mechanism of CA showed three competitive pathways. ${ }^{27}$ The minority fragment was formed by the high-energy pericyclic activation mechanism. The elimination of $\mathrm{CO}_{2}$ was not observed as the resulting ion would be a vinylic anion of low stability. As expected, the metabolite ion at $\mathrm{m} / \mathrm{z} 303$ did not shown the same fragmentation profile after LC-ESI-IT analysis (Figure 6.2). The MS/MS spectrum of the metabolite (Figure 6.2) showed the $\mathrm{CO}_{2}$ elimination as one important fragment. The pericyclic reaction was not observed, and the next ion was formed by neutral elimination of the side chain. These data together lead us to suggest an internal cyclization leading to the formation of a third cycle, as in isopimaran skeletons, which also do not present the pericyclic reaction. Therefore, the new putative metabolite structure identified as a CA isomer may have been formed by attacking the double bond and forming the third ring.

\section{CONCLUSIONS}

The current findings suggest high extraction ratio of CA and KA in the human liver, which means that at each passage through the liver the diterpenes are extensively biotransformed into metabolites. The systemic biological activity described for both the oleoresin ${ }^{3,28-30}$ and the isolated acid diterpenes in vivo ${ }^{31}$ after oral or parenteral administration are probably resultant from active metabolites than the unchanged diterpenes. Our data have shown that the metabolism profile was similar when comparing RLM and HLM for both CA and KA, which highlighted the RLM as a good model for this investigation. Potential metabolites for KA and CA were resulting from HLM were described here. Further experiments to assess the activity and targets for these metabolites might be of interest to support the traditional use and to advance the drug development.

\section{ACKNOWLEDGMENTS}

This study was partially financed by the Coordenação de Aperfeiçoamento de Pessoal de Nível Superior - Brasil (CAPES)

Table 4. Accurate mass data of KA, CA and its metabolites obtained by in vitro metabolism with RLM and HLM

\begin{tabular}{lcccc}
\hline Diagnostic ion & Chemical formula & $\mathrm{m} / \mathrm{z}$ calculated & $\mathrm{m} / \mathrm{z}$ observed & Error $(\mathrm{ppm})$ \\
\hline KA $[\mathrm{M}-\mathrm{H}]^{-}$ & $\mathrm{C}_{20} \mathrm{H}_{29} \mathrm{O}_{2}$ & 301.2173 & 301.2171 & 0.6 \\
KA rat metabolite $[\mathrm{M}-\mathrm{H}]^{-}$ & $\mathrm{C}_{20} \mathrm{H}_{31} \mathrm{O}_{4}$ & 335.2228 & 335.2225 & 0.8 \\
KA human metabolite $[\mathrm{M}-\mathrm{H}]^{-}$ & $\mathrm{C}_{20} \mathrm{H}_{31} \mathrm{O}_{4}$ & 335.2228 & 335.2233 & -1.7 \\
$\mathrm{CA}[\mathrm{M}-\mathrm{H}]^{-}$ & $\mathrm{C}_{20} \mathrm{H}_{31} \mathrm{O}_{2}$ & 303.2330 & 303.2328 & 0.5 \\
CA rat metabolite $[\mathrm{M}-\mathrm{H}]^{-}$ & $\mathrm{C}_{20} \mathrm{H}_{31} \mathrm{O}_{2}$ & 303.2330 & 303.2326 & 1.3 \\
CA human metabolite $[\mathrm{M}-\mathrm{H}]^{-}$ & $\mathrm{C}_{20} \mathrm{H}_{31} \mathrm{O}_{2}$ & 303.2330 & 303.2335 & -2.0 \\
\hline
\end{tabular}



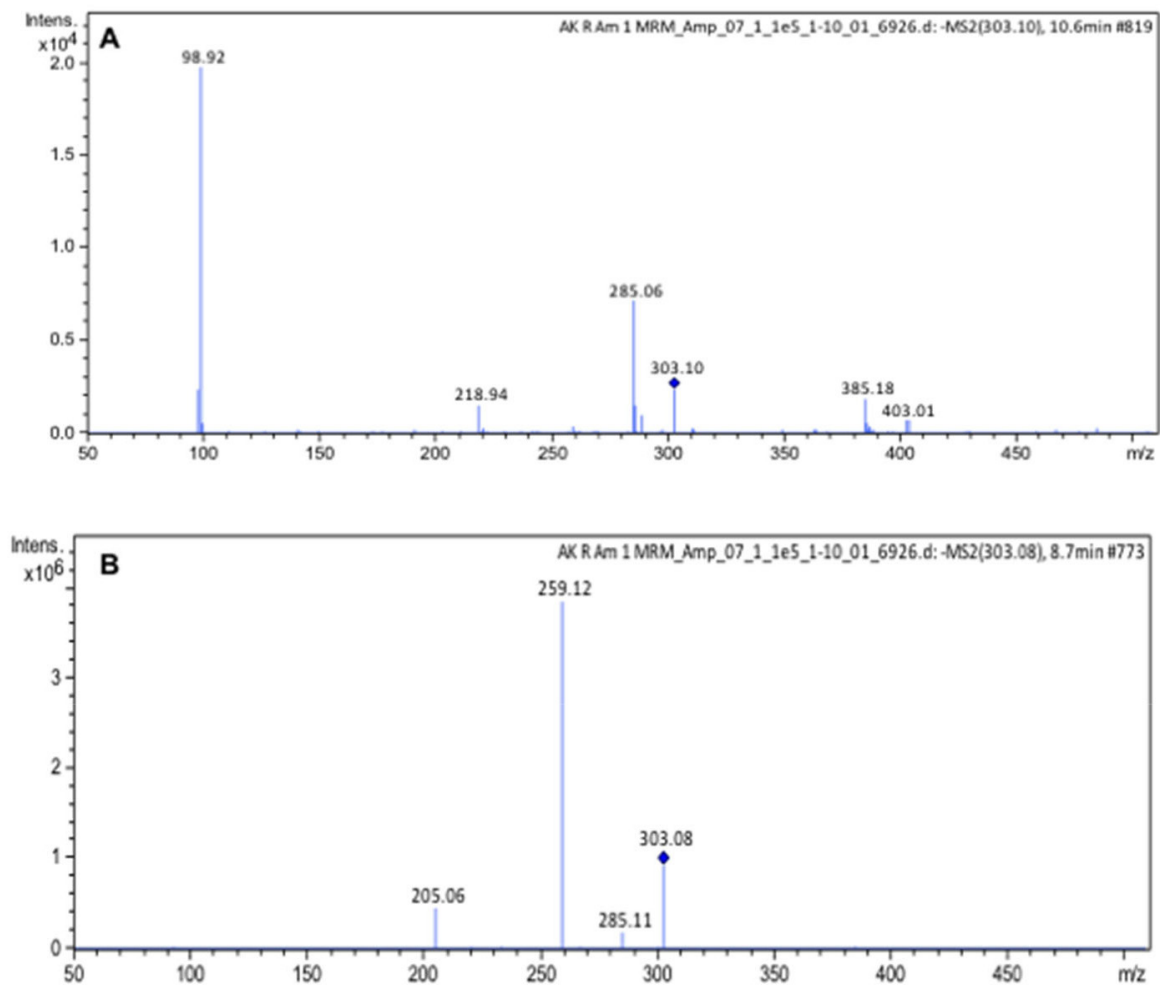

Figure 5. Fragmentation mass spectrum of $C A(A)$ and CA metabolism product in RLM (B), obtained by LC-ESI-IT analysis

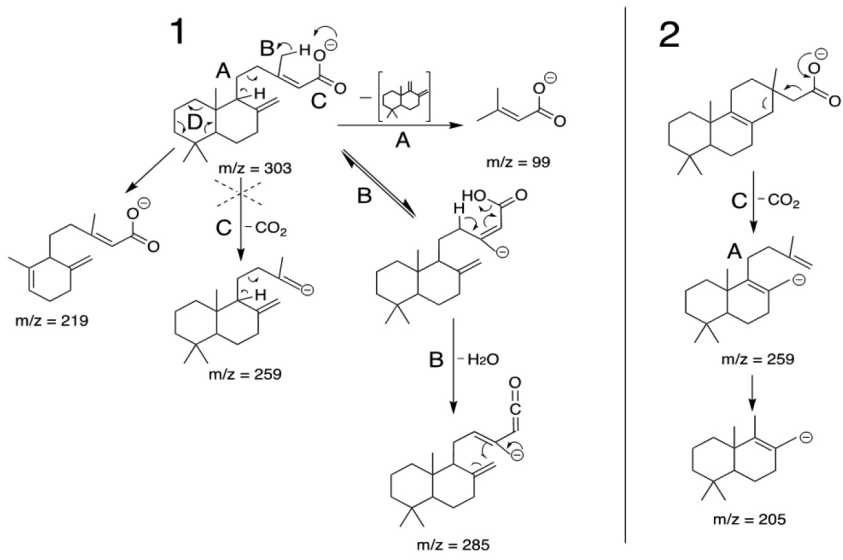

Figure 6. Fragmentation pathway of copalic acid (1) and the putative metabolite (2)

- Finance Code 001. The authors are grateful to São Paulo Research Foundation (FAPESP), grant number 14/50265-3.

\section{REFERENCES}

1. Breitbach, U. B.; Niehues, M.; Lopes, N. P.; Faria, J. E. Q.; Brandão, M. G. L.; J. Ethnopharmacol. 2013, 147, 180.

2. Nakamura, M. T.; Endo, E. H.; De Sousa, J. P. B.; Callejon, D. R.; UedaNakamura, T.; Dias Filho, B. P.; De Freitas, O.; Nakamura, C. V.; Lopes, N. P.; J. Braz. Chem. Soc. 2017, 28, 1377.

3. Basile, A. C.; Sertié, J. A.; Freitas, P. C.; Zanini, A. C.; J. Ethnopharmacol. 1988, 22, 101.

4. Veiga Jr, V. F.; Zunino, L.; Calixto, J. B.; Patitucci, M. L.; Pinto, A. C.; Phytother. Res. 2001, 15, 476.

5. Paiva, L. A.; Gurgel, L. A.; Silva, R. M.; Tomé, A. R.; Gramosa, N. V.; Silveira, E. R.; Santos, F. A.; Rao, V. S.; Vasc. Pharmacol. 2002, 39, 303.
6. Veiga Jr, V. F.; Rosas, E. C.; Carvalho, M. V.; Henriques, M. G. M. O.; Pinto, A. C.; J. Ethnopharmacol. 2007, 112, 248.

7. Gomes, N. M.; Rezende, C. M.; Fontes, S. P.; Matheus, M. E.; Pinto, A. C.; Fernandes, P. D.; J. Ethnopharmacol. 2010, 128, 177.

8. Sousa, J. P.; Brancalion, A. P.; Souza, A. B.; Turatti, I. C.; Ambrósio, S. R.; Furtado, N. A.; Lopes, N. P.; Bastos, J. K.; J. Pharm. Biomed. Anal. 2011, 54,653 .

9. Ito, K., Houston, J. B.; Pharm. Res. 2005, 22, 103.

10. Mauro, M.; De Grandis, R. A.; Campos, M. L.; Bauermeister, A.; Peccinini, R. G.; Pavan, F. R.; Lopes, N. P.; De Moraes, N. V.; J. Ethnopharmacol. 2019, 235, 183.

11. Fernandes, E. F. A.; Oliveira, A. R. M.; Barros, V. P.; Guaratini, T.; Lopes, N. P.; Rev. Bras. Farmacogn. 2020, 30, 551.

12. Srikanth, C. H.; Chaira, T.; Sampathi, S. V. B. S.; Bambal, R. B.; Analyst 2013, 138, 6106.

13. Obach, R. S. Drug Metab. Dispos. 1999, 27, 1350; Kumar, S.; Samuel, K.; Subramanian, R.; Braun, M. P.; Stearns, R. A.; Chiu, S. L.; Evans, D. C.; Baillie, T. A.; J. Pharmacol. Exp. Ther. 2002, 303, 969.

14. Seibert, E.; Tracy, T. S. In Enzyme Kinetics in Drug Metabolism: Fundamentals and Applications; Nagar, S., Argikar, U. A., Tweedie, D. J., eds.; Springer Protocols: Haftfield, 2014.

15. Houston, J. B.; Kenworthy, K. E.; Drug Metab. Dispos. 1999, 28, 246.

16. Nakamori, F.; Naritomi, Y.; Furutani, M.; Takamura, F.; Miura, H.; Murai, H.; Terashita, S.; Teramura, T.; Drug Metab. Pharmacokinet. 2011, 26, 465; Obach, R. S.; Baxter, J. G.; Liston, T. E.; Silber, B. M.; Jones, B. C.; Macintyre, F.; Rance, D. J.; Wastall, P.; J. Pharmacol. Exp. Ther. 1997, 283, 46.

17. Wan, H.; Bold, P.; Larsson, L. O.; Ulander, J.; Peters, S.; Löfberg, B.; Ungell, A. L.; Någård, M.; Llinàs, A.; Curr. Drug Metab. 2010, 11, 583.

18. Tozer, T. N.; Rowland, M. In Introduction to pharmacokinetics and pharmacodynamics: the quantitative basis of drug therapy; Tozer, T. N., Rowland, M., eds.; Lippincott Williams \& Wilkins: Baltimore, 2006.

19. Heuberger, J.; Schmidt, S.; Derendorf, H.; J. Pharm. Sci. 2013, 102, 3458. 
20. Lee, K. J.; Mower, R.; Hollenbeck, T.; Castelo, J.; Johnson, N.; Gordon, P.; Sinko, P. J.; Holme, K.; Lee, Y. H.; Pharm. Res. 2003, 20, 1015.

21. Deitchman, A. N.; Singh, R. S. P.; Derendorf, H.; J. Pharm. Sci. 2018, 107,754 .

22. Gertz, M.; Kilford, P. J.; Houston, J. B.; Galetin, A.; Drug Metab. Dispos. 2008, 36, 535.

23. Denisov, I. G.; Baas, B. J.; Grinkova, Y. V.; Sligar, S. G.; J. Biol. Chem. 2007, 282, 7066 .

24. Hutzler, J. M.; Tracy, T. S.; Drug Metab. Dispos. 2002, 30, 355.

25. Huang, W.; Lin, Y. S.; Mcconn, D. J.; Calamia, J. C.; Totah, R. A.; Isoherranen, N.; Glodowski, M.; Thummel, K. E.; Drug Metab. Dispos. 2004, 32, 1434.

26. da Cunha Pinto, A.; Vessecchi, R.; da Silva, C. G.; Amorim, A. C.; dos Santos Júnior, H. M.; Rezende, M. J.; Gates, P. J.; Rezende, C. M.; Lopes, N. P.; Rapid Comm. Mass. Spectrom. 2016, 30, 61.

27. Aguiar, G. P.; Crevelin, E. J.; Dias, H. J.; Ambrósio, S. R.; Bastos, J. K.; Heleno, V.; Vessecchi, R.; Crotti, A.; J. Mass Spectrom. 2018, 53, 1086.
28. Veiga Jr, V. F.; Zunino, L.; Patitucci, M. L.; Pinto, A. C.; Calixto, J. B.; J. Pharm. Pharmacol. 2006, 58, 1405.

29. Campos-Carraro, C.; Turck, P.; de Lima-Seolin, B. G.; Tavares, A.; Dos Santos Lacerda, D.; Corssac, G. B.; Teixeira, R. B.; Hickmann, A.; Llesuy, S.; da Rosa Araujo, A. S.; Belló-Klein, A.; J. Cardiovasc. Pharmacol. 2018, 72, 214.

30. Barbosa, M.; Vicentini, F. A.; Castro-Ghizoni, C. V.; Lameira, O. A.; Sa-Nakanishi, A. B.; Bracht, L.; Peralta, R. M.; Natali, M.; Bracht, A.; Comar, J. F.; Endocr. Metab. Immune Disord. Drug Targets 2018, 18, 268.

31. Paiva, L. A. F.; De Alencar Cunha, K. M.; Santos, F. A.; Gramosa, N. V.; Silveira, E. R.; Rao, V. S.; Phytother. Res. 2002, 16, 737; Okoye, T. C.; Akah, P. A.; Omeje, E. O.; Okoye, F. B.; Nworu, C. S.; Pharmacol. Biochem. Behav. 2013, 109, 38. 